\title{
Indirect method for measurement of leaf area and leaf area index of soilless cucumber crop
}

\begin{abstract}
The plant parameters such as leaf area (LA) or leaf area index (LAI) play an important role in understanding photosynthesis, light interception, water and nutrient use and crop growth. A better understanding of the relationships between crop development and environment is thus important. Both LA and LAI can be measured directly by using digital meters (destructive methods) or indirectly using developed regression techniques (non-destructive methods). In the present study, non-destructive methods (regression equations) were developed for estimation of LA and LAI separately. The developed regression equations were used to estimate LA and LAI. Both LA and LAI predictions presented a high precision and accuracy. The developed non-destructive methods for estimation of LA and LAI were found functional for cucumber crop with a significant saving in energy and time.
\end{abstract}

Keywords: Cucumber, greenhouse, leaf area, leaf area index, soilless
Volume 8 Issue 2 - 2018

\author{
Mahesh Chand Singh, KG Singh, JP Singh \\ Department of Soil and Water Engineering, Punjab Agricultural \\ University, India
}

\author{
Correspondence: Mahesh Chand Singh, Ph.D. Student, \\ Department of Soil and Water Engineering, Punjab Agricultural \\ University, Ludhiana-141004, Punjab, India, \\ Email mahesh_25_pau@yahoo.co.in
}

Received: November 01, 2017 | Published: April 04, 2018

\section{Introduction}

Leaf area is one of the important parameters in understanding photosynthesis, light interception, water and nutrient use and crop growth. ${ }^{1,2}$ It is thus important to measure accurately the leaf area of cucumber crop for better understanding of the relationships between crop development and environment. ${ }^{3}$ The leaf area can be measured by direct and indirect methods. In direct methods (destructive methods), leaves are removed from the plant and measurements are done using expensive tools such as digital leaf area meter. However, the non-destructive methods (regression techniques) based on linear measurements of plant leaves are relatively accurate, quicker and effortless to be implemented in several crops. ${ }^{4-6}$ indirect methods are useful for small plant populations, such as the plants grown in pots or grow bags and allow for repeated measurements of the same plants during the plant growth period. Blanco \& Folegatti ${ }^{7}$ developed a non-destructive methodology to estimate the leaf area index (LAI) of cucumber and tomato plants by evaluating the leaf area distribution pattern of the plants and the relative height of the leaves in plants. Cho et al. ${ }^{8}$ successfully developed regression models to predict area of individual leaf, fresh weight and dry weight of a cucumber using leaf length, leaf width and SPAD value as input. Xu et al. ${ }^{9}$ presented a model for predicting LAI of greenhouse crops including cucumber based on the quantification of easily measured morphological traits as affected by temperature and radiation. However, not much effort has been made on indirect measurement of leaf area and leaf area index in past particularly under soilless cropped conditions. A study was thus undertaken to develop a non-destructive methodology (indirect method) for estimating the LA and LAI for greenhouse cucumber plants, based on linear measurements (regression techniques)

\section{Materials and methods}

The study was conducted inside a naturally ventilated greenhouse located at research farm of department of Soil and Water Engineering, Punjab Agricultural University (PAU), Ludhiana. The study site is situated between latitude $30^{\circ} 56^{\prime} \mathrm{N}$ and longitude $75^{\circ} 52^{\prime} \mathrm{E}$ with an altitude of $247 \mathrm{~m}$ above mean sea level. Cucumber crop (Multistar) was cultivated for two successive growing seasons during 2016-17. A 216 ready cucumber plants were transplanted at 3-4 leaf stage during both growing seasons. The plants were trained vertically up by means of string attached to the roller hooks. Cucumber was fertigated with nutrient solution on daily basis for a predetermined time throughout the growth period. The fertigation included three levels viz. $100 \%$ (F1), 85\% (F2) and 70\% (F3) of nutrient solution under optimal microclimatic conditions. The climate of the study area can be classified as tropical steppe, hot and semi-arid which is mainly dry with very hot summer and cold winter except during monsoon season. The normal annual rainfall of the district is $680 \mathrm{~mm}$ with uneven distribution. The south west monsoon sets in from last week of June and withdraws in end of September, contributes about 70-80 percent of annual rainfall with July and August being the wettest months.

\section{Data measurement}

The data on leaf area and leaf area index (LAI) was recorded at a regular interval of time. The height of cucumber plant and leaf dimensions was recorded on weekly basis using a measuring tape or scale. Leaf area index (LAI) was also measured at a regular interval of 15 days using Sun Scan (type SS1, AT Delta-T Devices, Cambridge England). For measurement of leaf dimensions (length and width), a total 27 leaves were selected (9 leaves from each replicate) and the process was repeated by selecting younger leaves at the end of life of older selected leaves. Leaf area was determined using graph or grid paper. While calculating leaf area, a box occupying area more than half the area of a complete square box was taken equal to area of a complete square box. The area of a half square box was taken exactly half the area of a complete square box, while the box occupying area less than half area of a complete square box was discarded.

\section{Leaf area}

Based on the leaf area calculated using grid or graph paper technique, a linear regression model of leaf area (LA) was developed. The leaf area of the cucumber was related to variable leaf dimensions (LA and LW). 


$$
L A=0.00409 \times\left(192.68 \times\left(\frac{L L}{100}\right) \times\left(\frac{L W}{100}\right)-1\right)
$$

Where, $L A$, Leaf area $\left(\mathrm{m}^{2}\right), L L$, Leaf length $(\mathrm{cm})$ and $L W$, Leaf width $(\mathrm{cm})$

The predicted leaf area from equation (1) was compared with observed leaf area data.

\section{Leaf area index}

The leaf area index (LAI) of cucumber was modeled into a linear relationship with the plant height as indicated by equation 2 .

$$
L A I=0.021 \times\left(31.48 \times\left(\frac{h}{100}\right)-1\right)
$$

Where, $h$, Plant height (m)

The leaf area index calculated from equation 2 was compared with the observed data.

The LA and LAI equations were developed and validated using the data for season 1 and season 2 respectively.

\section{Statistical analysis}

The performance of developed methods for LA and LAI was evaluated by calculating root mean square error (RMSE), coefficient of determination $\left(R^{2}\right)$ and Model efficiency $\left(\eta_{e f f}\right)$.

\section{Root mean square error}

$$
R M S E=\sqrt{\frac{1}{n} \sum\left(P_{i}-O_{i}\right)^{2}}
$$

\section{Coefficient of determination}

The coefficient of determination $\mathrm{R} 2$ varies from 0 to 1 and describes the degree of association between observed and predicted values.

$$
R^{2}=\frac{\left[\sum_{i=1}^{N}\left(O_{i}-\overline{O_{i}}\right)\left(P_{i}-\overline{P_{i}}\right)\right]^{2}}{\sum_{i=1}^{N}\left(O_{i}-\overline{O_{i}}\right)^{2} \sum_{i=1}^{N}\left(P_{i}-\overline{P_{i}}\right)^{2}}
$$

\section{Model efficiency}

The model efficiency was calculated using equation given in Nash and Sutcliffe. ${ }^{10}$

$$
\eta_{e f f}=\left\{1-\frac{\sum_{i=1}^{n}\left(P_{i}-O_{i}\right)^{2}}{\sum_{i=1}^{n}\left(O_{i}-\overline{O_{i}}\right)^{2}}\right\} \times 100
$$

\section{Results and discussion}

\section{Leaf area}

The leaf area of cucumber plant is one of the important parameters which indicate the periodic plant growth rate. Here, the leaf area of the greenhouse parthenocarpic cucumbers showed a vigorous growth throughout the growth period. Comparisons were made between measured and predicted leaf area and a good agreement was obtained with a percent error in the range of 0.8-8.2. In general, the model underestimated the leaf area during first half and overestimated during second half life of the leaf. Figure 1 demonstrates the comparison between observed and predicted leaf area for Multistar. In all figures, the vertical error bars (y-axis) represent the standard deviation value of 1.0. Figures 1-3 demonstrate the comparison between observed and predicted leaf area respectively at 13,20 and 27 DAT.

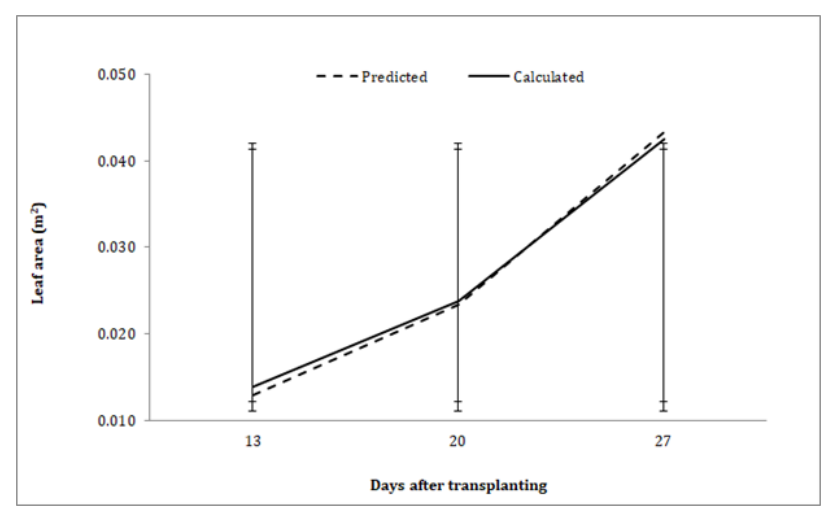

Figure I Predicted and observed leaf area cucumber for 100\% level of fertigation.

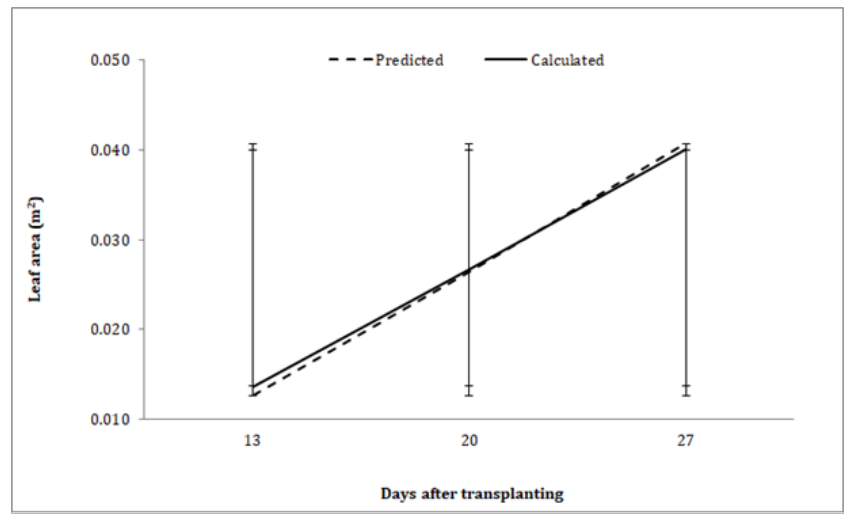

Figure 2 Predicted and observed leaf area for $85 \%$ level of fertigation.

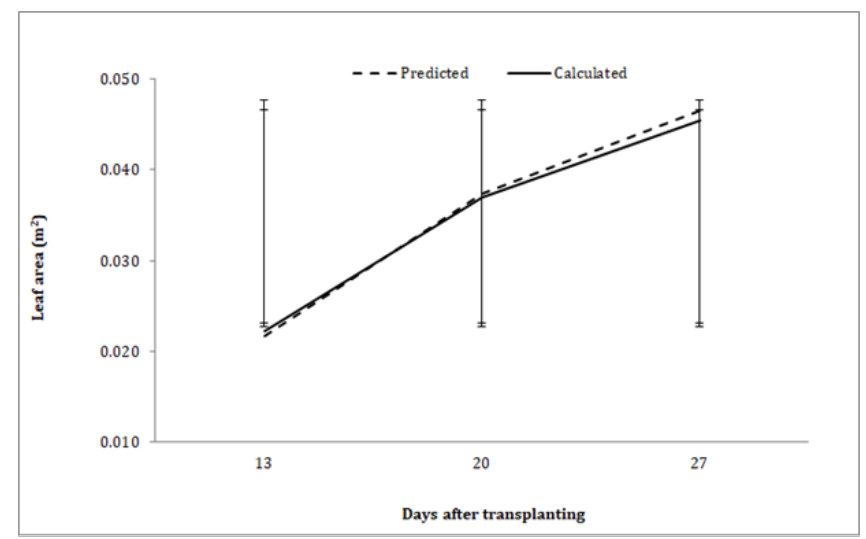

Figure 3 Predicted and calculated leaf area for $70 \%$ level of fertigation.

\section{Variation of plant height with time}

Plant height is one of the main indicators of crop growth and productivity ${ }^{11}$ as observed in the present case. The average minimum 
and maximum plant height was recorded to be $1.2 \mathrm{~m}$ and $3.7 \mathrm{~m}$ at 11 and 95 DAT respectively during season.

1. The plant height remained statistically similar among the fertigation treatments during season.

2. The maximum height was recorded under F2 (Figure 4A) Similar to season 1, the plant height among fertigation treatments was found statistically similar throughout the growth period. The average minimum and maximum plant height was recorded to be $0.2 \mathrm{~m}$ and $4.0 \mathrm{~m}$ at 13 and 90 DAT respectively during season

3. The maximum height was recorded under F3 (Figure 4B).

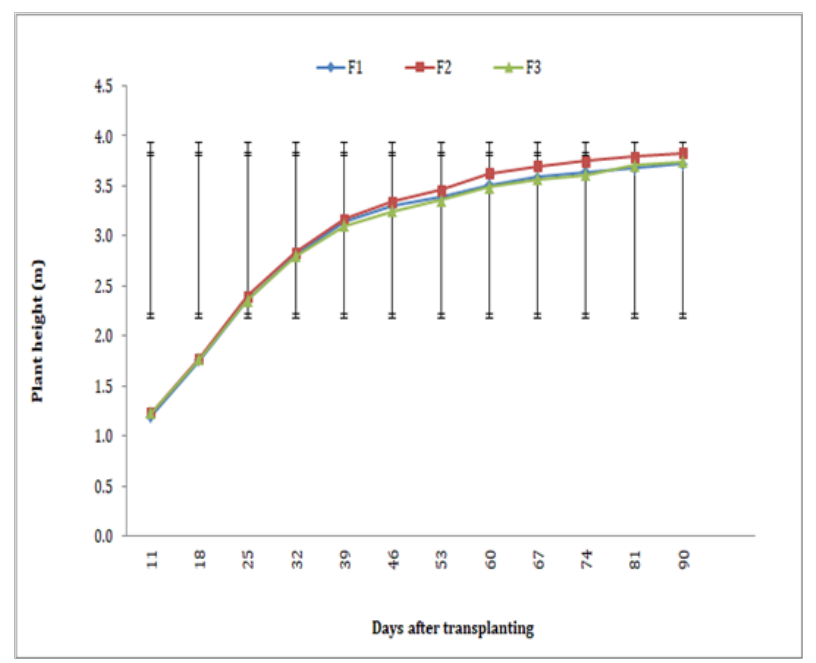

Figure 4 (A) Variation of plant height with DAT during season I.

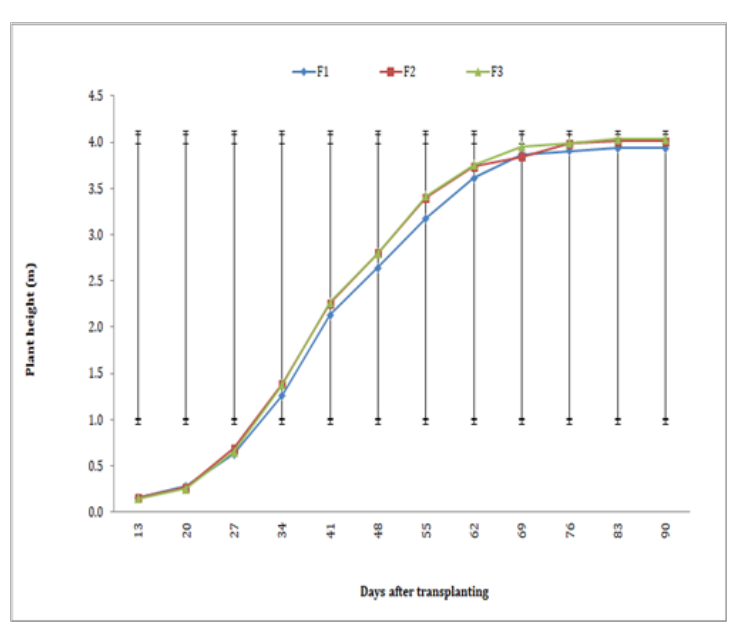

Figure 4 (B) Variation of plant height with DAT during season 2.

\section{Plant Leaf area index (LAI)}

The structural design of plant canopy (e.g. LAI) significantly affects the plant development and yield through its effect on light interception. ${ }^{12}$ LAI critically affects the plant metabolic activities, biomass production, transpiration and greenhouse gas sequestration. ${ }^{13}$ However, the direct measurement of LAI is quite difficult, time consuming and labor intensive. Thus, under such circumstances, the indirect methods can play an important role in measurement of LAI. The LAI predictions made from the developed regression model in the present study were in a good agreement with the observed data during both growing seasons. Figure 5 demonstrates the comparison between observed and predicted LAI data. The coefficient of determination $\left(R^{2}\right)$, model efficiency $\left(\eta_{\text {eff }}\right)$ and root mean square error (RMSE) during season 1 and season 2 were $0.96,90.0 \%, 0.13$ and 1.0, $98.4 \%, 0.13$ respectively. The developed regression equations were used to estimate the leaf area and LAI separately. Both LA and LAI predictions presented a high precision and accuracy. The developed regression models were functional for cucumber crop with a significant saving in energy and time. On the basis of previous studies, LAI has been considered as one of the crucial factors which affect the plant metabolic activities through its effect on irrigation or fertigation management due to improper VPD and crop transpiration. ${ }^{14-17}$ Thus, this type of studies in relation to greenhouse microclimatic conditions could be helpful in monitoring and management of greenhouse crop water requirement in soilless culture through optimization of factors limiting the crop growth and productivity. ${ }^{18,19}$

Figure 5 Predicted and observed LAl of cucumber.

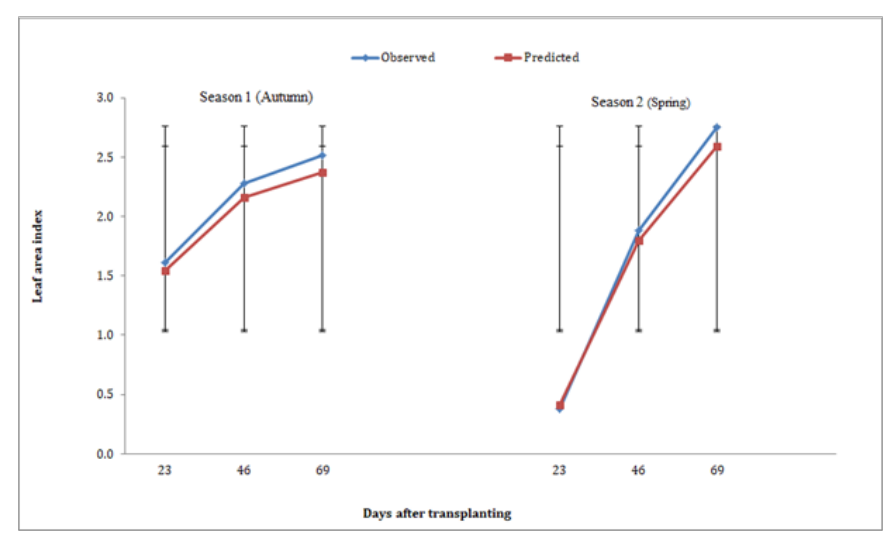

\section{Conclusion}

The developed equations were used to estimate the leaf area and LAI separately. On comparisons, the measured and predicted leaf area data were in good agreement with the percent error in the range of 0.8-8.2. Similarly, the measured and predicted LAI were also in good agreement with average model efficiency $\left(\eta_{e f f}\right)$ and root mean square error (RMSE) values of $94.2 \%$ and 0.13 respectively. Both LA and LAI predictions presented a high precision and accuracy. The developed regression models were functional for cucumber crop with a significant saving in energy and time.

\section{Acknowledgement}

The authors wish to acknowledge the support from the funding agency, ICAR, New Delhi under AICRP Project on Plasticulture Engineering and Technology.

\section{Conflict of interest}

None.

\section{References}

1. Smart RE. Photosynthesis by grapevine canopies. Journal of Applied Ecology. 1974;11(3):997-1006.

2. Williams LE. Growth of Thompson Seedless" grapevines: I. Leaf area development and dry weight distribution. Journal of American Society of Horticulture Science.1987;112:325-330.

3. de Jesus WC Jr, Do Vale FXR, Coelho RR, et al. Comparison of two 
methods for estimating leaf area index on common bean. Agronomy Journal. 2001;93(5):989-991.

4. Strik BC, Proctor JTA. Estimating the area of trifoliolate and unequally imparipinnate leaves of strawberry. HortScience.1985;20:1072-1074.

5. Norman JM, Campbell GS. Canopy structure. In: Pearcyr W, Ehleringer, editors. Plant physiological ecology. Field methods and Instrumentation. Chapman and Hall, London and New York, 1989; pp. 301-325.

6. Guo DP, Sun YZ. Estimation of leaf area of stem lettuce (Lactuca sativa var angustana) from linear measurements. Indian Journal of Agricultural Science. 2001;71(7):483-486.

7. Blanco FF, Folegatti MV. A new method for estimating the leaf area index of cucumber and tomato plants. Horticultura Brasileira. 2003;21(4):666-669.

8. Cho YY, Oh S, Oh MM, et al. Estimation of individual leaf area, fresh weight and dry weight of hydroponically grown cucumbers (Cucumis sativus L.) using leaf length, width, and SPAD value. Scientia Horticulturae. 2007;111:330-334.

9. $\mathrm{Xu} \mathrm{R}$, Dai J, Luo W, et al. A photothermal model of leaf area index for greenhouse crops. Agricultural Forest Meteorology.2010;150(4):541-552.

10. Nash JE, Sutcliffe JV. River flow forecasting through conceptual models. Part I. A discussion of Principles. Journal of Hydrology. 1970;10(3):282-290

11. Boonekamp G. Search for a better cucumber system. Fruit and Vegetable Technology. 2005;5(2):10-11.

12. Wiechers D, Kahlen K, Stutzel H. Evaluation of a radiosity based light model for greenhouse cucumber canopies. Agricultural and Forest Meteorology. 2011;151(7):906-915.
13. Colaizzi PD, Evett SR, Brauer DK, et al. Allometric method to estimate leaf area index for row crops. Agronomy Journal. 2017;109(3):883-894.

14. Medrano E, Lorenzo P, Sanchez-Guerrero MC, et al. Evaluation and modelling of greenhouse cucumber-crop transpiration under high and low radiation conditions. Scientia Horticulturae. 2005;105(2):163175 .

15. Singh MC, Yusuf A. Singh JP Greenhouse microclimate modelling under cropped conditions-A review. Research in Environment and Life Sciences. 2016;9:1552-1557.

16. Singh MC, Singh JP, Pandey SK, et al. Factors affecting the performance of greenhouse cucumber cultivation-a review. International Journal of Current Microbiology and Applied Sciences. 2017a;6(10):2304-2323.

17. Singh MC, Singh JP. Singh KG. Optimal operating microclimatic conditions for drip fertigated cucumbers in soilless media under a naturally ventilated greenhouse. Indian Journal of Ecology. 2017b;44:821-826.

18. Singh MC, Singh JP, Pandey SK, et al. A Review of Three Commonly Used Techniques of Controlling Greenhouse Microclimate. International Journal of Current Microbiology and Applied Sciences. 2018a;7(1):3491-3505

19. Singh MC, Kachwaya DS, Kalsi K. Soilless cucumber cultivation under protective structures in relation to irrigation coupled fertigation management, economic viability and potential benefits-A review. International Journal of Current Microbiology and Applied Sciences 2018b;7(3):2451-2468. 